\title{
Infrastructure Sharing as an Opportunity to Promote Competition in Local Access Networks
}

\author{
João Paulo Pereira ${ }^{1}$ and Pedro Ferreira ${ }^{2}$ \\ ${ }^{1}$ School of Technology and Management, Polytechnic Institute of Bragança (IPB), 5301-857 Bragança, Portugal \\ ${ }^{2}$ Institute for Systems and Robotics, Technical University of Lisbon (IST), 1049-001 Lisbon, Portugal \\ Correspondence should be addressed to João Paulo Pereira, jprp@ipb.pt
}

Received 8 October 2011; Revised 8 January 2012; Accepted 21 February 2012

Academic Editor: John Doucette

Copyright ( 2012 J. P. Pereira and P. Ferreira. This is an open access article distributed under the Creative Commons Attribution License, which permits unrestricted use, distribution, and reproduction in any medium, provided the original work is properly cited.

\begin{abstract}
Telecom infrastructures are facing unprecedented challenges, with increasing demands on network capacity. Today, network operators must determine how to expand the existing access network infrastructure into networks capable of satisfying the user's requirements. Thus, in this context, providers need to identify the technological solutions that enable them to profitably serve customers and support future needs. However, the identification of the "best" solution is a difficult task. Although the cost of bandwidth in the active layer has reduced significantly (and continually) in recent years, the cost of the civil works-such as digging and trenching - represents a major barrier for operators to deploy NGA infrastructure. Duct is a critical part of the nextgeneration access networks, and its sharing would reduce or eliminate this capital cost and this barrier to entry. The aim of this paper is to provide a better understanding of the economics of broadband access networks technologies (wireline and wireless), their role in the deployment of several services in different regions, and the development of competition in the access networks.
\end{abstract}

\section{Introduction}

The need for telecommunication networks with higher capacity is becoming a reality all over the world. However, there is a recognized disparity between broadband availability in urban and rural areas. Preexisting rural telecommunications infrastructure is generally poor and unevenly distributed in favor of urban centers [1]. In most rural areas, low population density and high deployment costs discourage private investment, creating a negative feedback of limited capacity, high prices, and low service demand. It is costly to build telecommunications networks in rural areas. Further, in many cases, there is not a good commercial business case for rural deployments; established, competitive service providers already offer solutions for urban and suburban areas, yet there is little or no commitment to connect areas that include smaller towns and rural villages [2]. The deployment of access network broadband services in low competition areas is characterized by low subscriber densities, longer loop lengths, lower duct availability, and, consequently, higher infrastructure costs compared to high competition areas.
The rapid development of new-generation applications requires upgrading the access infrastructure a necessity for higher throughput requirements and communication demands. These applications include high-definition television (HDTV), peer-to-peer (P2P) applications, video on demand, interactive games, e-learning, and use of multiple personal computers (PCs) at home. Other ubiquitous broadband access requires a minimum bit rate sufficient to allow all citizens to benefit from these services. As a result, to run voice, data, video, and advanced Internet applications, residential users might soon need connections of more than 30 Mbps [3].

Service and network providers are challenged to provide this higher-capacity access to the end user and offer wider services. Consequently, new Internet infrastructure and technologies that are capable of providing high-speed and highquality services are needed to accommodate multimedia applications with diverse QoS requirements. Until a few years ago, Internet access for residential users was almost exclusively provided via public switched telephone networks (PSTN) over the twisted copper pair [4]. The new quadruple 
play services (i.e., voice, video, data, and mobility) require high-speed broadband access, which created new challenges for the modern broadband wireless/wired access networks [5]. The new services led both to the development of several different last-mile solutions to make the access network capable of supporting the requirements and to a stronger integration of optical and wireless access networks.

\section{Next-Generation Networks (NGNs)}

The move toward NGNs has significant implications for the technical architecture and design of access network infrastructure, as well as the value chains and business models of electronic communications service provision [6]. This migration has begun to transform the telecommunication sector from distinct single-service markets into converging markets [7]. NGNs allow consumers to choose from among different access network technologies to access their service environment. In our work, the NGN architecture will be limited to the current and future developments of network architectures in the access network (local loop), referred to as the "next-generation access network" (NGAN).

2.1. Next-Generation Access Networks. NGANs are being deployed across the world with technologies, such as fiber, copper utilizing xDSL technologies, coaxial cable, power line communications (PLC), wireless solutions, or hybrid deployments of these technologies. Wireless networks typically use a range of different technologies, including high speed packet access (HSPA), HSPA+, worldwide interoperability for microwave access (WiMAX), and long-term evolution (LTE). Further, wireline networks increasingly employ some form of fiber, such as fiber-to-the-home (FTTH) and fiberto-the-curb/cabinet (FTTC). NGN access in a fixed network is initially broadband access-based on the copper loops; however, many countries are in the process of enhancing these networks over time to provide higher speed using fiberbased technology, such as very high-speed digital subscriber line (VDSL) or FTTB/H. For cable networks, often the only voice service is IP based, whereas for mobile networks, the migration to IP voice is more complex [6].

2.2. Competition in Next-Generation Access. The choice of a specific technology for NGAN can be different among countries, geographic areas, and operators. In recent years, there has been an increase in the number, coverage, and market share of "alternative" networks or operators, such as resellers, unbundling operators, cable network operators, operators using frequencies for WLL/WiMAX, and operators deploying optical fiber in the local loop [8]. This has resulted in differences in competitive conditions among geographic areas, leading to increasing arguments (especially from incumbent operators) that geographical aspects should be recognized in market/competition analyses and regulatory decisions. There are several factors that might be responsible for this discrepancy [9]: state and age of the existing network infrastructure; length of the local loop; population density and structure of the housing market; distribution of the number of users and street cabinets for local exchange; level of intermodal competition in the market; willingness to pay for broadband services; existence of ad hoc national government plans for broadband development.

\section{Model Overview}

3.1. Description. The proposed model compares seven NGA broadband technologies-FTTH-PON, xDSL, HFC, PLC, Fixed WiMAX, UMTS, and LTE-in different scenarios, focusing on the access segment of the network (between CO and customer premises). Some assets within the access network include (1) feeder, distribution segment, and the final drop connection to the customer's premises (we assume that the cost associated with final drop connection is included in the activation fee of the service); (2) trenches/ducts from $\mathrm{CO}$ and customer premises; (3) cable (optical fiber, copper, and coax) in feeder and distribution part of the network; (4) radio systems (wireless solutions); (5) equipment, such as repeaters, line cards, DSLAMs, ONU, and OLTs.

The programming language used to implement the model was Microsoft Excel with Visual Basic for Applications (VBA), which includes all relevant capital and operating expenditures for the several technologies. The proposed tool calculates the required total expenditure in terms of CAPEX, OPEX, and other several economic indicators.

3.2. Model Structure. The proposed model is divided into four main parts (Figure 1): input parameters, engineering model (applies engineering criteria to determine the volumes of components), economic model (provides information for several kinds of information), and a sensitivity analysis model that shows the effects of uncertainties.

\section{Business Case (Case Study) Definition}

The definition of a "business case" implies a great number of assumptions, such as the penetration rate, components prices, and the market share rate. However, it is difficult to get an exact forecast of its performance. The utility of a business case is offering a more approximated estimation that allows for the construction of future scenarios. It is fundamental that the business case be as realistic as possible to be useful and reflect all the variables of interest of the market as well as its own evolution and expected behavior [11].

In each business case, several scenarios can be defined by network alternatives, service portfolio, market segments, and external factors such as regulatory issues, competition, and demand evolution [12]. A "scenario" is the description of the network situation to provide a given set of services to a number of users within a certain area and study period, including one or several operators $[13,14]$. In summary, the scenario description is defined in terms of regulation, services, competition, and technology. Scenariobased technoeconomics uses scenarios to estimate several economic results of a technology in different circumstances.

4.1. Main Assumptions and Input Parameters. The first step is to collect all input relevant to the business case. Each network 


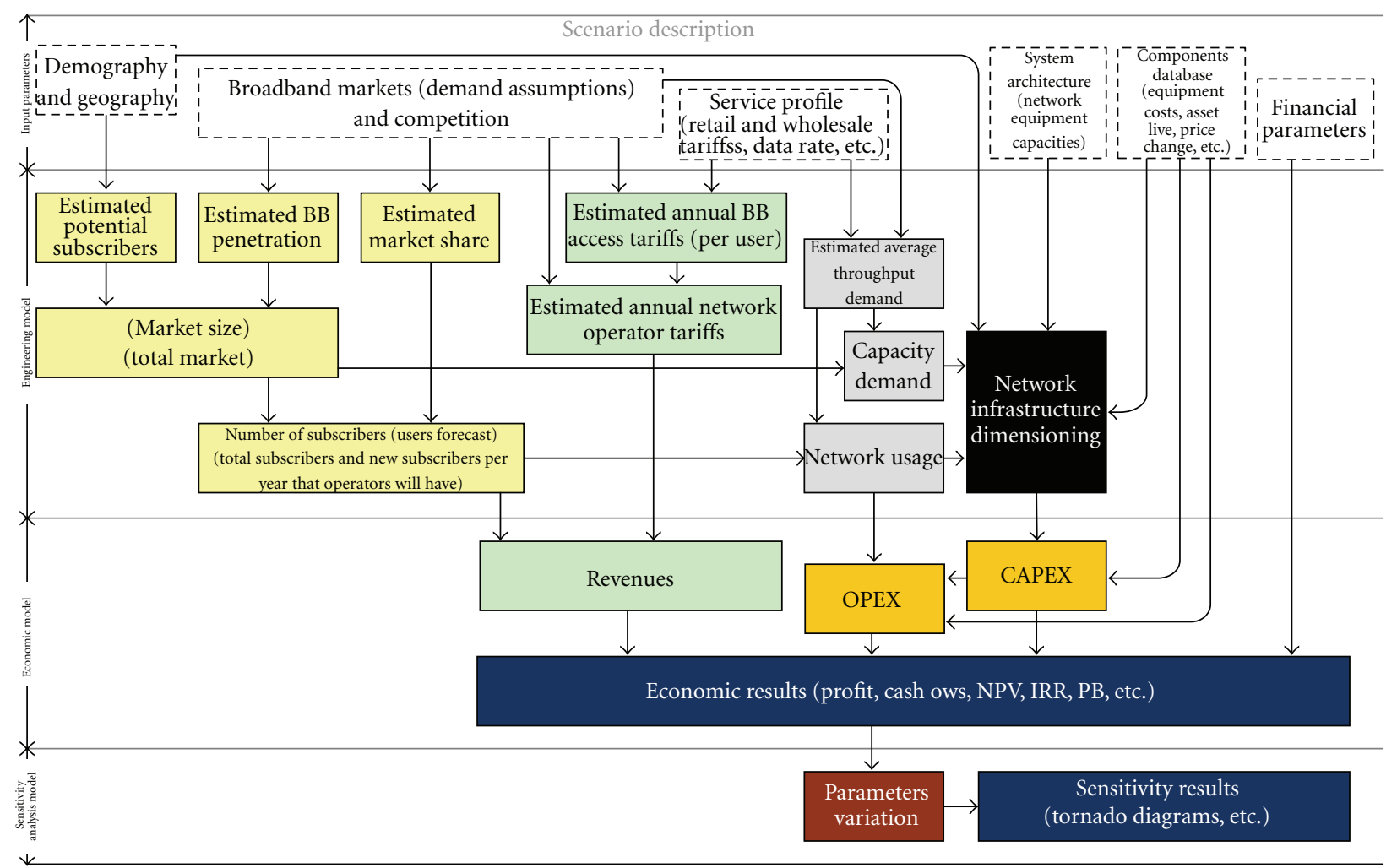

FIgURE 1: Model structure [10].

deployment has a unique set of financial, technical, and business parameters that need to be modeled and analyzed [15]. The base case was developed to study the costs and other economic results of two technologies (FTTH: PON and LTE) in two different regions (urban and rural) and different competitive markets. The analysis horizon is 10 years.

The network is built for the total number of homes passed in advance of subscriber turn on (fixed costs). All construction work (trench, ducts, cable, cabinets, base stations, etc.) required to provide service to all homes passed takes place in the first year. Therefore, all infrastructure costs (e.g., housing construction, electronics, and cable deployment) are incurred for all homes passed. Equipment is deployed based on take rate assumptions. This implies that in areas with low penetration rates, the cost per subscriber would be higher than at high take rates, where it would be low [16]. However, the deployment costs of the CPE, the drop cable/installation, and the ports in the aggregate node are incurred only when a home subscribes (marginal costs). We also assume there is maximum sharing of trenching, which means that all wires run over a common trench for as far as possible. The method used to calculate the reduction factor for trench sharing is based on previous Europe economic projects [17]. Table 1 presents the main general assumptions considered for the business case.

4.2. Territory and Demography. For the rural area, the rollout strategy does not cover the whole area; the target area is limited to $34.04 \mathrm{~km}^{2}$ with 23,000 inhabitants (see Table 2).
Several studies and models $[19,20]$ assume that in urban areas, the duct availability rate is about $60 \%$ for feeder segments and $40 \%$ for the distribution segment. In rural areas, the duct availability rate is $25 \%$ for feeder and $0 \%$ for the distribution segment. The report from Analysys-Mason [21] assumes that a substantial proportion ( $80 \%$ near to the $\mathrm{CO}$ and $30 \%$ nearer to the premises) of existing ducts can be reused for fiber deployment (see Table 3 ).

For mobile solutions, [22] assumes a site sharing of $90 \%$ in urban areas (lower in less-populated areas) as regulation declares that masts for UMTS must be shared between operators.

4.3. Service Profiles Assumptions. Service profile is key driver of the business model, and some assumptions have to be made. The service profile drives the revenue and traffic forecasts, and the traffic forecast drives capital and operating expenses. The traffic generated by users is required to calculate economic results. For all services, we need to define the type (e.g., triple play and phone), bandwidths, mobility, and so on.

So, as the network services are used and the number of users connected in the network is increasing, the throughput demand tends to grow quite rapidly over time. Several studies propose some $20 \%$ to $50 \%$ growth every year in the long run [14, 23-26]. Since the average traffic demand per user is increasing exponentially, the network is initially dimensioned for the whole demand growth in the study period. 
TABLE 1: General assumptions summary.

\begin{tabular}{ll}
\hline Input assumption & Description \\
\hline Analysis horizon & 10 years \\
\hline Operator type & $\begin{array}{l}\text { Incumbent, CLEC (Competitive Local } \\
\text { Exchange Carrier) and new entrants }\end{array}$ \\
\hline & $\begin{array}{l}\text { Urban coverage and rural coverage. An } \\
\text { urban area was chosen due to the } \\
\text { high-density population and to the high } \\
\text { data demand. A rural area was chosen } \\
\text { due to its low-density population and its } \\
\text { relatively low service demand compared } \\
\text { with urban areas. }\end{array}$ \\
profiles & $\begin{array}{l}\text { The cost model considers two different } \\
\text { technological options for the provision of } \\
\text { next-generation broadband services: }\end{array}$ \\
\hline FTTH(PON) and LTE. We assume that \\
each region has only one CO.
\end{tabular}

TABLE 2: Territorial and demographic scenarios.

\begin{tabular}{lcc}
\hline Parameters & Region 1 & Region 2 \\
\hline Geographic area type & Urban & Rural \\
Size of Area: Surface $\left(\mathrm{km}^{2}\right)$ & 45.90 & 1.173 \\
Population & 172,063 & 34.000 \\
Trend (\% per year) & $0.62 \%$ & $-0.04 \%$ \\
Density (pop $\left./ \mathrm{km}^{2}\right)$ & 3.748 & 29 \\
\hline Target area & & \\
Target area $\left(\mathrm{km}^{2}\right)$ & 45.90 & 34.04 \\
Target Population & 172.063 & 23.000 \\
Trend $(\%$ per year) & $0.62 \%$ & $0.01 \%$ \\
Density (pop/km $\left.{ }^{2}\right)$ & 3,748 & 676 \\
Inhabitants per household & 1.99 & 1.54 \\
Total no. of potential subscribers $(\mathrm{HH})$ & 86.565 & 14.921 \\
Number of buildings in serving area & 18.249 & 6.596 \\
\hline
\end{tabular}

Let us assume the growth ratio of throughput demand to be $1.12(12 \%)$ per year for Service 2 and 1.1 (10\%) per year for Service 1 (see Table 4).

As the average traffic demand per user increases, the network is initially dimensioned for the whole demand growth in the study period.
TABLE 3: Infrastructure reuse assumptions [18].

\begin{tabular}{lc}
\hline Component & $\begin{array}{c}\text { Proportion of existing infrastructure } \\
\text { reused }\end{array}$ \\
\hline Feeder segment duct & $50 \%$ \\
Distribution segment & $80 \%$ \\
duct & $50 \%$ \\
Final drop & $100 \%$ \\
Street cabinet & \\
\hline
\end{tabular}

TABLE 4: Service profile technical features.

\begin{tabular}{lcc}
\hline Service profiles & $\begin{array}{c}\text { Data rate per subscriber } \\
(\mathrm{Mbps})\end{array}$ & $\begin{array}{c}\text { Annual } \\
\text { variation }\end{array}$ \\
\hline Service 1 & $2(\mathrm{DS}) / 0.200(\mathrm{US})$ & $10 \%$ \\
Service 2 & $20(\mathrm{DS}) / 2$ (US) & $12 \%$ \\
\hline
\end{tabular}

The expected tariff evolution (factor by which the tariff is expected to increase or decrease annually) is defined for both tariffs (see Table 5). We assume that one provider charges the same retail price in all regions. We observe that several studies and deployments [27-29] use the yearly price erosion of between $5 \%$ and $15 \%$.

4.4. Broadband Market Penetration (Penetration Rates). It is challenging to forecast the number of subscribers an operator can expect to sign over the life of the network. Specially, it is hard to predict consumers' behavior when faced with new technologies, new services, or if is required to opt for a new provider of that service [30].

For fixed broadband, the European research project CELTIC/MARCH estimates a penetration rate of $67.2 \%$ in 2018 (60\% in 2010). As we can see in Figure 2, the fixed broadband penetration is reaching a saturation level. For mobile broadband, the long-term broadband saturation level in the consumer market (Western EU) is estimated to be between $32 \%$ [31] and 34\% [28, 32, 33] in 2020. In 2010, the average penetration in Western EU was $6 \%$ and is estimated that penetration will be $20 \%$ in 2015 [34]. During the study period, there will be churn effect caused by mobile broadband substitution. Reference [28] argues that specific reasons are the cheaper prices of mobile broadband compared with fixed broadband. The market forecast is based on Gompertz model. Figures 2 and 3 show the penetration forecast for fixed and mobile technologies. In 2020, the expected penetration rates for the fixed technologies are $1.5 \%$ for WiMAX, $14.25 \%$ for HFC, $22.71 \%$ for fiber, and $30.97 \%$ for DSL.

To better plan the network capacity, we also segment the estimated broadband penetration into services classes; it is important to characterize how many subscribers are assigned to each service in each region/segment. We estimate that in Year 1, 40\% of all subscribers in the urban area (for the residential market segment) are assigned to Service 1 ( $2 \mathrm{Mbps}$ ) and $60 \%$ are Service 2 (20 Mbps). We also assume that market share of Service 1 has a decrease about $5 \%$ in the urban area and $3 \%$ in the rural area. 
TABle 5: Service profile characteristics (retail prices).

\begin{tabular}{lcccc}
\hline Service profiles & Activation fees & Annual variation & Monthly fees & Annual variation \\
\hline Service 1 & $100 €$ & $-5 \%$ & $20 € /$ month & $-5 \%$ \\
Service 2 & $100 €$ & $-5 \%$ & $50 € /$ month & $-7 \%$ \\
\hline
\end{tabular}

TABLE 6: FTTH (PON) architecture components by category.

\begin{tabular}{ll}
\hline Cost categories & Costs \\
\hline Equipment costs & (1) OLT (ports and chassis); (2) splitter (primary split); (3) splitter (secondary split); (4) ONU; \\
& (5) fiber modem; (6) optical repeater. \\
Installation costs (Equip.) & (1) OLT (ports and chassis); (2) splitter (primary split and secondary split); (3) ONU and \\
& CPE; (4) optical repeater. \\
Housing costs & Cost of building remote nodes—splitter cabinet/closures (secondary split). The cost for \\
building the CO is not included. & Cost of the labor required and include (1) trenching costs (digging and ducting costs) of feeder \\
aivil works (Labor ) & and distribution plant; (2) cable installation—pulling (cable not included) the cable on the \\
& feeder and distribution plant. \\
Cable costs & Cost of the necessary fiber optics (installation not included). Include the fiber cable required \\
& for the feeder and distribution plant.
\end{tabular}

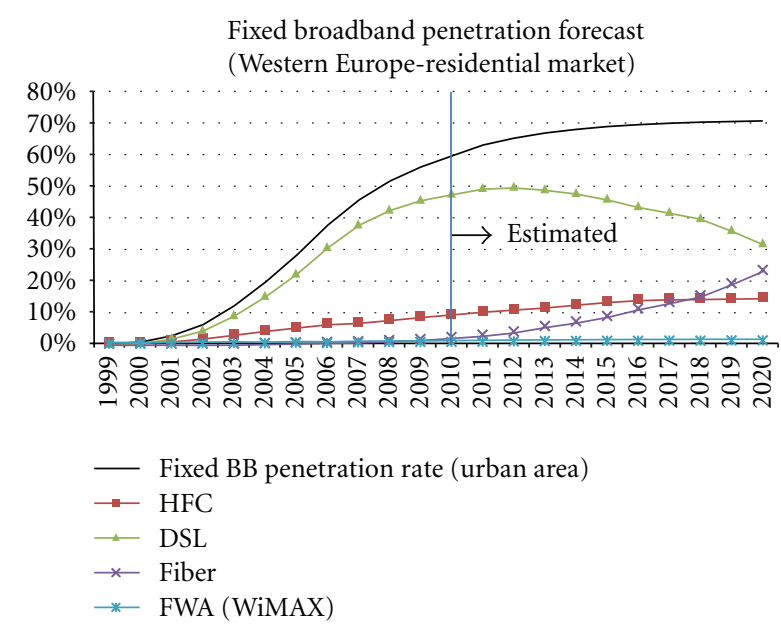

Figure 2: Fixed BB penetration forecasts (residential market).

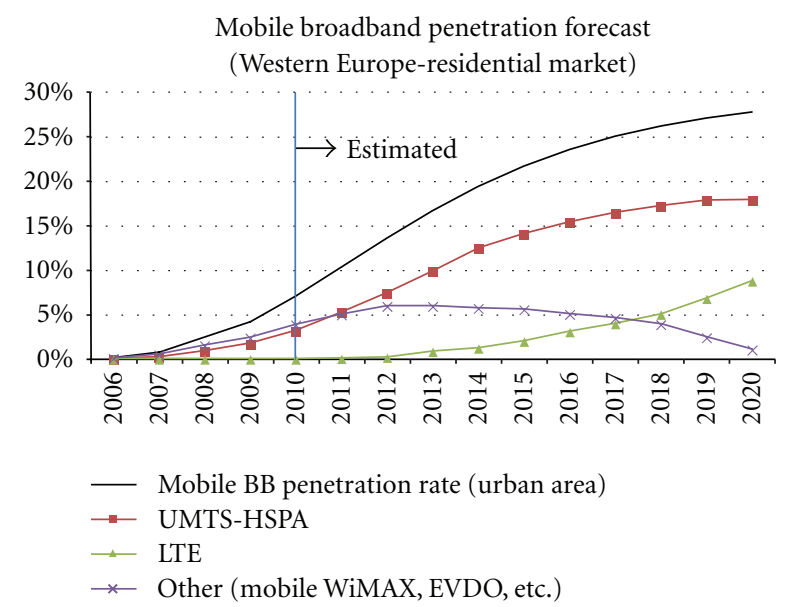

FIgURE 3: Mobile BB penetration forecasts (residential market).
4.5. Competition and Market Share (Deployment Strategies). In this section, we define the number of competitors (players) in the service operator market, the number of competitors (players) in the network operator market, and the market shares of the competitors.

In the urban area, the new entrant is faced with three players (competitors) in broadband fixed access technologies and three competitors in the broadband mobile access technologies: (1) DSL: one incumbent operator and one competitive operator (also known as alternative operators). It is assumed that the three operators (incumbent, competitive, and new entrant) control the entire market (100\%); (2) HFC: one incumbent operator; (3) UMTS: three incumbent operators. In the rural market, the new entrant has one competitor in broadband fixed access technologies and three competitors in the broadband mobile access technologies: (1) DSL: one incumbent operator; (2) UMTS: three incumbent operators.

\section{Network Architecture Assumptions}

With this business case, we want to compare two solutions (FTTH: PON and LTE) from the point of view of the existent competitors and a new entrant (i.e., an operator that does not have its own network infrastructure in the service area). Figure 4 shows the architecture defined in our case.

5.1. Network Components. For FTTH architecture, we assume that in the central office, the OLT card (with one or several ports) ensures the interface between the switching equipment and the ODN (Optical Distribution Network). The OLT line cards are aggregated on shelves that are placed in racks. The OM (Optical Monitoring) module surveys the ODN quality and an MDF (Main Distribution Frame), which provides a connection point between equipment and outside cables. For outside plant construction, it is necessary to consider the hardware parts (fiber cables, splices, splitters, connectors, and enclosures) together with civil work (e.g., 


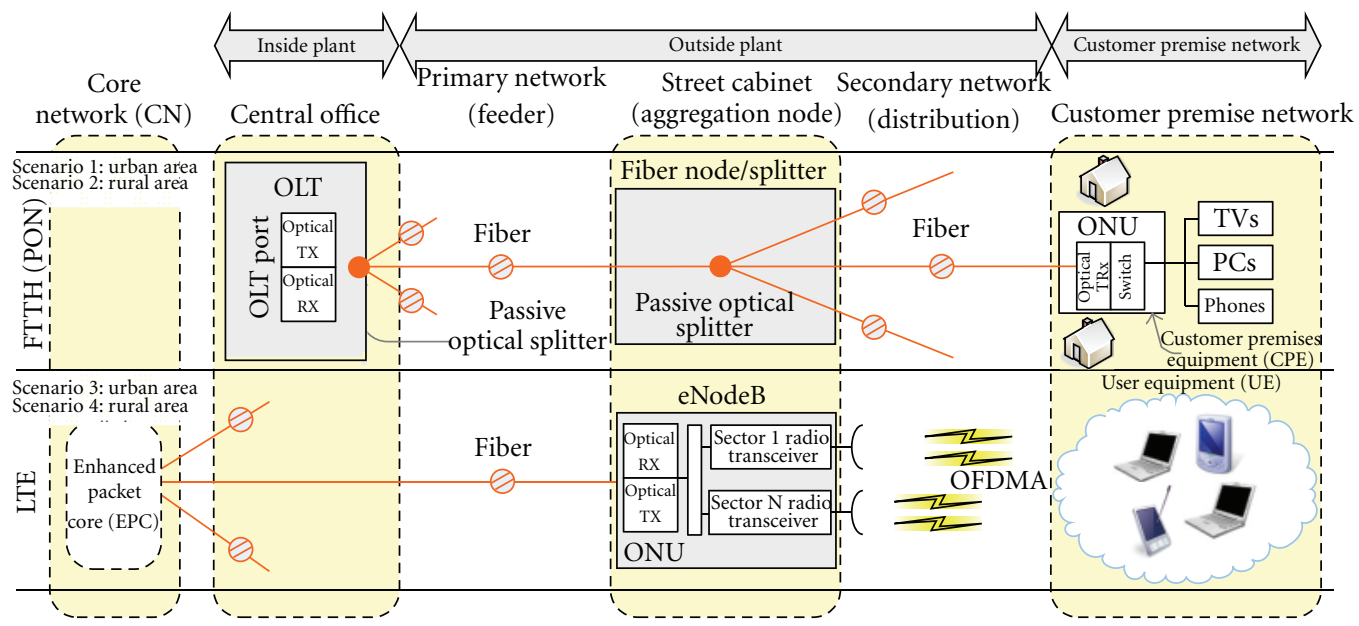

FIGURE 4: Broadband access network architecture.

TABLE 7: LTE architecture components.

\begin{tabular}{ccl}
\hline \multicolumn{2}{c}{ Segment } & Components \\
\hline Evolved Packet Core (EPC) & $\begin{array}{l}\text { OLT ports; chassis; splitter (primary split); installation (ports, } \\
\text { chassis, and split). }\end{array}$ \\
\hline & $\begin{array}{c}\text { Feeder } \\
\text { (EPC-eNodeB) }\end{array}$ & $\begin{array}{l}\text { Optical repeater; repeater installation; aerial/buried trenches/ducts } \\
\text { (trenching costs); fiber cable (cable cost); cable installation. }\end{array}$ \\
& eNodeB & $\begin{array}{l}\text { Site acquisition or site lease; civil works BS/cabinets; housing } \\
\text { cabinet/closures for each BS; TRXs; BS installation cost (including } \\
\text { sectors); ONU (per BS) and installation. }\end{array}$ \\
& Wistribution & Wireless PMP access \\
\hline \multirow{2}{*}{ End User } & & $\begin{array}{l}\text { LTE terminal (include antenna, transceiver, radio modem) and } \\
\text { installation. }\end{array}$ \\
\hline
\end{tabular}

TABle 8: CAPEX costs.

\begin{tabular}{|c|c|c|c|}
\hline Component name & Cost value & Installation cost & Source \\
\hline \multicolumn{4}{|l|}{ Equipment costs per unit } \\
\hline Fiber modem & $80 €$ & $100 €$ & CSMG \\
\hline Fiber splitter & $100 €$ & $50 €$ & CSMG \\
\hline Fiber OLT card (Ports32) & $60000 €$ & $20 €$ & CSMG \\
\hline OLT Chassis cards 32 & $5000 €$ & $150 €$ & CSMG \\
\hline Fiber Optical repeater & $10000 €$ & $60 €$ & Optilab \\
\hline Fiber_ONU & $106 €$ & $50 €$ & CSMG \\
\hline LTE_CPE & $75 €$ & $100 €$ & LUCENT \\
\hline LTE ENodeB & $34000 €$ & & WiROI LTE \\
\hline LTE TRX & $5000 €$ & $1000 €$ & WiROI LTE \\
\hline \multicolumn{4}{|l|}{ Housing (structure) } \\
\hline FNode Cab. 512user & $2450 €$ & & CSMG \\
\hline FNode Cab. 2048user & $3200 €$ & & CSMG \\
\hline LTE Site BuildOut & $17000 €$ & & WiMAX Forum \\
\hline \multicolumn{4}{|l|}{ Civil works costs } \\
\hline Digging/ducting costs: urban (per km) & $\begin{array}{c}60000 €(\text { urban }) \\
40000 €(\text { rural })\end{array}$ & CSMG & \\
\hline LTE_BS_CivilWorks & $1000 €$ & & WiMAX Forum \\
\hline \multicolumn{4}{|l|}{ Cable costs (per km) } \\
\hline OpticalCable24Fiber & $1220 €$ & $900 €$ & Analysys Mason \\
\hline OpticalCable96Fiber & $2934 €$ & $900 €$ & Analysys Mason \\
\hline
\end{tabular}


TABLE 9: Operation and administration costs (OPEX).

\begin{tabular}{|c|c|c|c|}
\hline Operation and administration costs & OAM cost & Assumptions & Source \\
\hline Equipment maintenance & $7.00 \%$ & of CAPEX for equipment & \multirow{6}{*}{ Analysys Consulting 2009} \\
\hline Installation equipment & $5.00 \%$ & of CAPEX for Installation & \\
\hline Housing: cabinets/closures & $5.00 \%$ & of CAPEX for closures & \\
\hline Cables (copper, coax, fiber) & $4.00 \%$ & of CAPEX for cables & \\
\hline Civil works & $3.00 \%$ & of CAPEX for Civil Works & \\
\hline Network operations & $10.00 \%$ & of gross revenue & \\
\hline \multirow{2}{*}{ Site rental, per MSC/GMSC } & & as: $3000 € /$ Year & \multirow{2}{*}{ EC 2009} \\
\hline & & as: $1000 € /$ Year & \\
\hline
\end{tabular}

TABLE 10: Technical assumptions.

\begin{tabular}{lc}
\hline Technical parameters & Value \\
\hline Downstream rate (Mbps) per OLT port & 622 \\
Upstream rate (Mbps) per OLT port & 155 \\
Number of OLT ports per Card & 08 \\
Number of OLT card slots per OLT Chassis & 16 \\
Primary split & 04 \\
Secondary split & 08 \\
Feeder cable type (Optical Cable) & 24 Fiber \\
Distribution cable type & 8 Fiber \\
Capacity per optical cable (Mbps) & 1000 \\
Distance between optical repeater (km) & 5 \\
Max. ONUs per OLT port & 64 \\
Max. nodeB per RNC & 100 \\
Max. capacity per RNC (Mbps) & 250 \\
\hline LTE (evolved node B) & \\
Maximum DS capacity per ONU (Mbps) & 2000 \\
Number of sectors per NodeB & 3 \\
Maximum number of TRX per sector & 6 \\
Max. Base Station range-radius (km) & 1.0 \\
Downstream TRX capacity (Mbps) & 20.00 \\
Upstream TRX capacity (Mbps) & 0.512 \\
\hline
\end{tabular}

trenching) and installation techniques. Each fiber cable is composed of several fibers.

Digging and ducting are the major cost items in access networks, outweighing by far the costs of the transmission medium and the line terminating equipment. Civil works typically take some $85 \%$ of fiber to the home (FTTH) first installed network costs, while the fiber cable and the optical components take only 3\%; the remainder is taken by other hardware, installation activities, and other services [35]. Hence, in Greenfield situations, the costs of introducing FTTH may not differ much from twisted copper pair or coaxial cable access solutions (see Table 6).

Based on LTE system architecture presented previously, the LTE system consists of two main blocks: the E-UTRAN and the EPC. The E-UTRAN segment is characterized by a network of eNBs that support OFDMA and advanced antenna techniques. Each eNB is composed of an antenna system (radio tower), building, and base station equipment (transceivers and antenna interface equipment). In the UE segment, users who connect using LTE mobile broadband will require an LTE modem to access the network, which will be available using PCMCIA cards; internally embedded modems inside laptops; ExpressCard; or a USB modem. Any users with mobile phones or PDA devices will also eventually have the ability to access the Internet using LTE mobile broadband services. For home Network Termination Units (NTUs), a receiver assembly that can produce one or more outputs can be connected to devices such as home telephones, computers, or television sets (see Table 7).

5.2. Capital Expense (CAPEX) Items. For each technology, a number of cost components are assigned to different parts of the networks. The major CAPEX components for each technology are described in Table 8. For each component cost, we also use a set of parameters required to calculate final costs, depreciation, economies of scale, and so on.

5.3. Operating Expense (OPEX) Items. Like network components costs, operation, and administration costs (OAM) have to be included in the calculations analyses. Table 9 presents the OPEX costs (per annum) as a percentage of initial CAPEX.

5.4. Technical Specifications. Several key network design assumptions used in our model are combined with the service profile as an additional input to the business model. These assumptions are presented in Table 10. These values are used to calculated network traffic, capital expenses, and operations expenses.

5.5. Scenarios. Several business case scenarios are studied and the economical results are presented (see Table 11).

\section{Business Case Evaluation (Results)}

In Scenario 9 (upgrade DSL/HFC to FTTH(PON), urban area), the NPV is positive (23 M€), IRR is $42 \%$, and payback period is five years. However, in the rural area (Scenario 10), the NPV and IRR are negative, and the payback period is greater than this study period (see Table 12).

Results show that the strategy of new entrant to deploy fiber deeper into the access network is not economically viable (Scenarios 11 and 12). In the urban area (Scenario 11), 
TABle 11: Scenarios description.

\begin{tabular}{ll}
\hline Scenario & Description \\
\hline $\begin{array}{l}\text { and } 10 \text { Upgrade } \\
11 \text { and } 12 \mathrm{New}\end{array}$ & $\begin{array}{l}\text { Upgrade of DSL to FTTH(PON) in both regions. This scenario analyses the incumbent player that has an } \\
\text { existing DSL network and aims evolve to FTTH(PON). } \\
\text { entrant }\end{array}$ \\
$\begin{array}{l}\text { New entrant deploy FTTH(PON) in both regions. BB access fiber deployment strategy used is the } \\
\text { infrastructure deployment (Fiber deployment deeper in the AN). } \\
\text { This scenario analyzes the incumbent player that has an existing UMTS network and wants to deploy its } \\
\text { own LTE network. Many operators already have 2G/3G networks with BS, which means that an important } \\
\text { part of the investments have been carried out. }\end{array}$ \\
$\begin{array}{l}\text { New entrant with LTE license in both regions. } \\
\text { entrant }\end{array}$
\end{tabular}

TABLE 12: General economic results: FTTH(PON).

\begin{tabular}{|c|c|c|c|c|c|c|}
\hline \multirow{3}{*}{ Indicator } & \multicolumn{3}{|c|}{ Region 1} & \multicolumn{3}{|c|}{ Region 2} \\
\hline & \multirow{2}{*}{$\begin{array}{l}\text { Scenario } 9 \\
\text { Operator } 1\end{array}$} & \multicolumn{2}{|c|}{ Scenario 11} & \multirow{2}{*}{$\begin{array}{l}\text { Scenario } 10 \\
\text { Operator } 1\end{array}$} & \multicolumn{2}{|c|}{ Scenario 12} \\
\hline & & Operator 2 & Operator 3 & & Operator 2 & Operator 3 \\
\hline Type of operator & Incumbent & New entrant & - & Incumbent & New entrant & - \\
\hline Payback period & 5 & $>$ Study Period & - & $>$ Study Period & $>$ Study Period & - \\
\hline Payback period (DCF) & 5 & $>$ Study Period & - & $>$ Study Period & $>$ Study Period & - \\
\hline NPV-year 10 & $23.525 .114 €$ & $77.930 .761 €$ & - & $2.891 .438 € €$ & $74.554 .064 €$ & - \\
\hline IRR & $42.60 \%$ & $-15.42 \%$ & - & $-2.69 \%$ & $-35.24 \%$ & - \\
\hline Cost per subsc. Y1 (CAPEX+OPEX) & $3.037 €$ & $92.052 €$ & - & $14.331 €$ & $3.494 .104 €$ & - \\
\hline Cost per subsc Yn (CAPEX+OPEX) & $102 €$ & $225 €$ & - & $68 €$ & $234 €$ & - \\
\hline Total 10-year cumulative CAPEX & $17.024 .848 €$ & $108.287 .583 €$ & - & $6.617 .710 €$ & $81.922 .300 €$ & - \\
\hline Total 10-year cumulative OPEX & $8.630 .924 € €$ & $7.914 .193 €$ & 一 & $892.505 €$ & $2.920 .012 €$ & - \\
\hline
\end{tabular}

TABLE 13: General economic results of FTTH(PON) with infrastructure sharing.

\begin{tabular}{|c|c|c|c|c|c|c|}
\hline \multirow{3}{*}{ Indicator } & \multicolumn{3}{|c|}{ Region 1} & \multicolumn{3}{|c|}{ Region 2} \\
\hline & \multirow{2}{*}{$\begin{array}{l}\text { Scenario } 9 \\
\text { Operator } 1\end{array}$} & \multicolumn{2}{|c|}{ Scenario 11} & \multirow{2}{*}{$\begin{array}{l}\text { Scenario } 10 \\
\text { Operator } 1\end{array}$} & \multicolumn{2}{|c|}{ Scenario 12} \\
\hline & & Operator 2 & Operator 3 & & Operator 2 & Operator 3 \\
\hline Type of operator & Incumbent & New entrant & - & Incumbent & New entrant & - \\
\hline Payback period & 4 & 10 & - & 7 & $>$ Study Period & - \\
\hline Payback period (DCF) & 5 & $>$ Study Period & - & 10 & $>$ Study Period & - \\
\hline NPV-year 10 & $28.631 .692 €$ & $6.494 .183 €$ & - & $359.689 €$ & $5.515 .438 € €$ & - \\
\hline IRR & $32.91 \%$ & $-4.30 \%$ & - & $1.82 \%$ & $-20.12 \%$ & - \\
\hline Cost per subsc. Y1 (CAPEX+OPEX) & $3.127 €$ & $25.595 €$ & - & $9.608 €$ & $287.934 €$ & - \\
\hline Cost per subsc Yn (CAPEX+OPEX) & $103 €$ & $193 €$ & - & $84 €$ & $261 €$ & - \\
\hline Total 10-year cumulative CAPEX & $15.922 .467 €$ & $31.696 .364 €$ & - & $4.470 .139 €$ & $7.122 .407 €$ & - \\
\hline Total 10-year cumulative OPEX & $9.632 .985 €$ & $7.012 .172 €$ & - & $1.067 .618 €$ & $2.367 .722 €$ & - \\
\hline
\end{tabular}

TABLE 14: General economic results of LTE.

\begin{tabular}{|c|c|c|c|c|c|c|}
\hline \multirow{3}{*}{ Indicator } & \multicolumn{3}{|c|}{ Region 1} & \multicolumn{3}{|c|}{ Region 2} \\
\hline & \multirow{2}{*}{$\begin{array}{l}\text { Scenario } 17 \\
\text { Operator } 1\end{array}$} & \multicolumn{2}{|c|}{ Scenario 19} & \multirow{2}{*}{$\begin{array}{l}\text { Scenario } 18 \\
\text { Operator } 1\end{array}$} & \multicolumn{2}{|c|}{ Scenario 20} \\
\hline & & Operator 2 & Operator 3 & & Operator 2 & Operator 3 \\
\hline Type of operator & Incumbent & New entrant & - & Incumbent & New entrant & - \\
\hline Payback period & 8 & $>$ Study Period & - & 9 & $>$ Study Period & - \\
\hline Payback period (DCF) & 10 & $>$ Study Period & - & $>$ Study Period & $>$ Study Period & - \\
\hline NPV-10 year & $741.070 €$ & $305.266 .868 €$ & - & $37.747 €$ & $38.237 .147 €$ & - \\
\hline IRR & $14.56 \%$ & $-30.02 \%$ & - & $10.99 \%$ & $-30.10 \%$ & - \\
\hline Cost per subsc. Y1 (CAPEX+OPEX) & $138.160 €$ & $7.776 .688 €$ & - & $151.019 €$ & $6.971 .479 €$ & - \\
\hline Cost per subsc Yn (CAPEX+OPEX) & $93 €$ & $110 €$ & - & $87 €$ & $104 €$ & - \\
\hline Total 10-year cumulative CAPEX & $5.254 .196 €$ & $330.436 .601 €$ & - & $793.222 €$ & $41.469 .144 € €$ & - \\
\hline Total 10-year cumulative OPEX & $1.902 .605 €$ & $25.798 .773 € €$ & - & $244.684 €$ & $3.145 .164 €$ & - \\
\hline
\end{tabular}




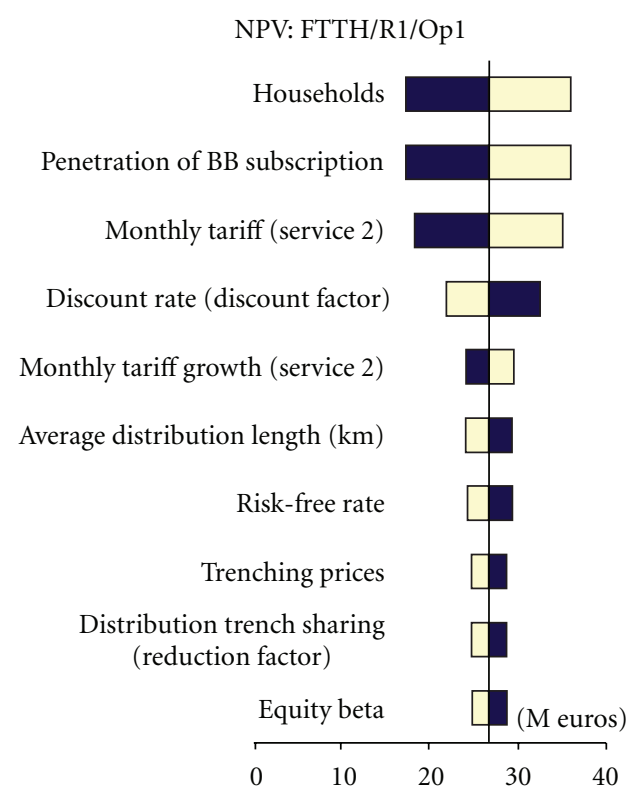

(a)

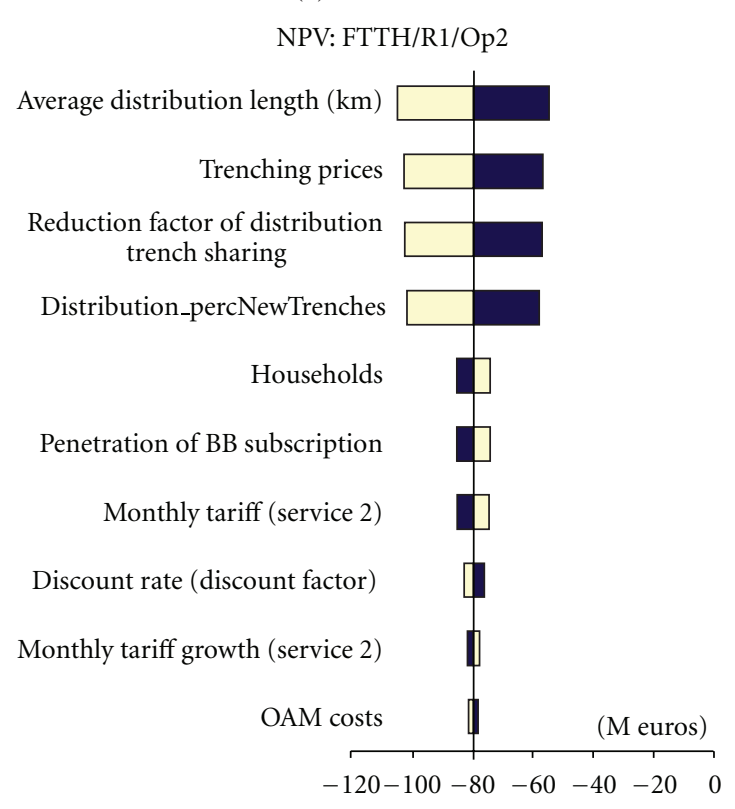

(b)

FIGURE 5: Sensitivity analysis results, FTTH(PON)/urban area/Op. 1 and 2.

the NPV is $-77.9 \mathrm{M} €$ and IRR is $-15.42 \%$. In Scenario 12 (rural area), the estimated NPV in the end of Year 10 is $-74.5 \mathrm{M} €$ and IRR is $-35.2 \%$. The cumulated CAPEX in Year 10 for the urban area is six times superior to the incumbent costs. In the rural area, the CAPEX is 13 times superior (see Table 12).

For Scenarios 11 and 12, we also compute the economic results when the new entrant uses the passive infrastructure (ducts) from the incumbent operator (see Table 13). Table 14 presents the economic results if the new entrant (Operator 2) decides to lease (instead of build) the ducts from incumbent

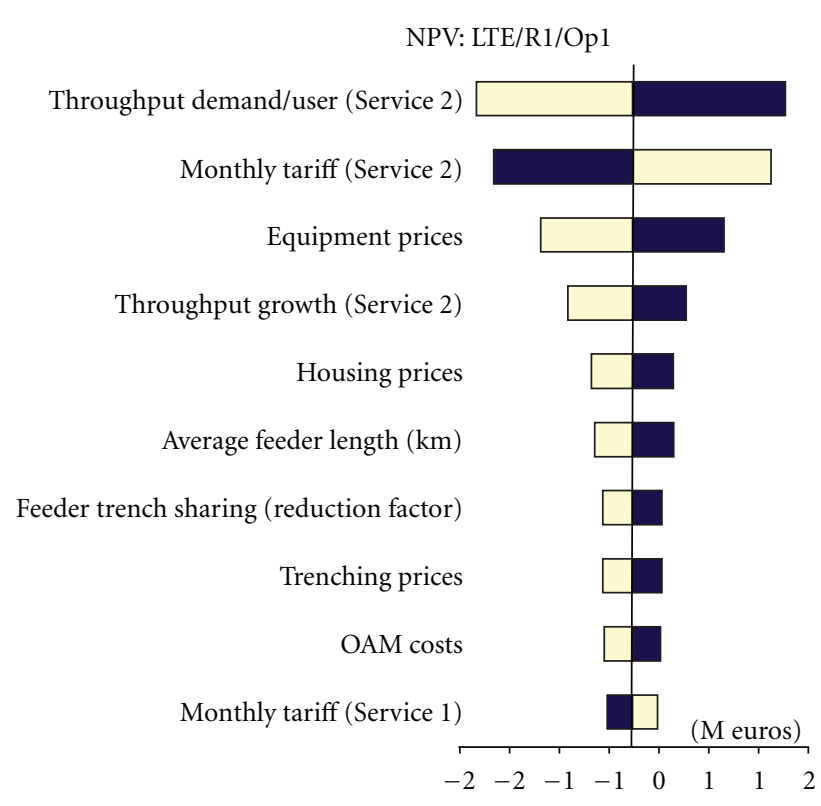

(a)

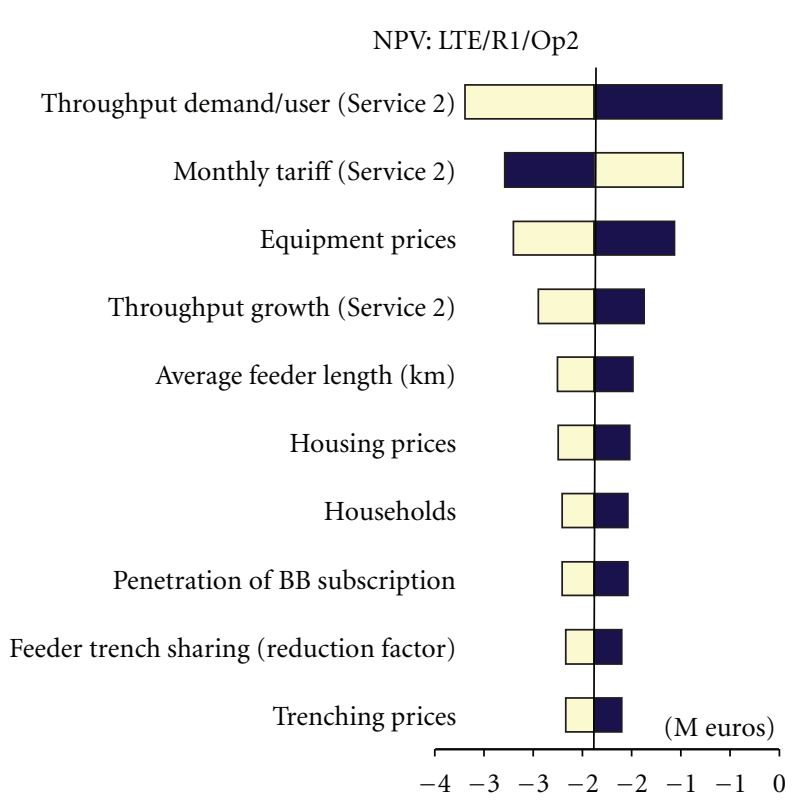

(b)

FIgURe 6: Sensitivity analysis results, LTE/rural area/Op. 1 and 2.

(Operator 1). We assume, in the urban area, duct availability (number of ducts available for leasing) of 100\% in the feeder segment and $100 \%$ in the distribution segment. For the rural area, we assume $75 \%$ and $75 \%$ for both feeder and distribution segments. The results clearly indicate that the economic results improve significantly. The NPV of Operator 1 increases from $23 \mathrm{M} €$ to $28.6 \mathrm{M} €$, and the payback period is reduced to 4 years; this occurs because of the value paid by Operator 2 to use Operator 1's infrastructure. Operator 2 also gets positive effects with the increase of NPV, about $70 \mathrm{M} €$, 


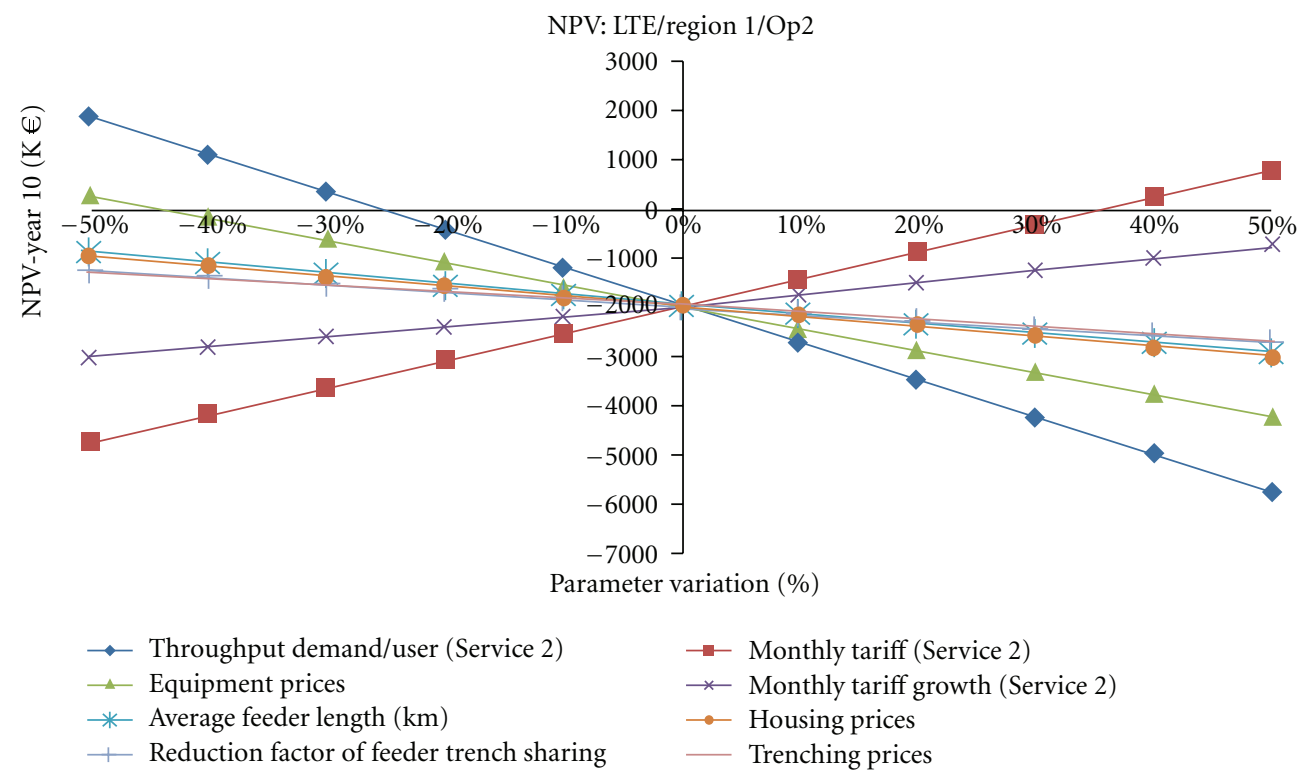

FIGURE 7: Sensitivity analysis results, LTE/urban area/new entrant.

a decrease in the payback period, and a significant reduction of CAPEX.

For LTE technology, we define two main scenarios (upgrade of UMTS network to LTE and the deployment of a new network by a new entrant) that are applied in both regions. In Scenario 17 (upgrade in the urban area), the NPV is positive but low, and the IRR is $14.5 \%$; the discounted payback period is estimated to be nine years. In the rural area (Scenario 18), the discounted payback period is greater than 10 years. The upgrade scenario in the rural area has a negative NPV, but the IRR is positive, although the Greenfield deployment (Scenarios 19 and 20) has higher costs in both regions. The IRR is negative and similar in both regions $(-30.02 \%$ and $-30.1 \%)$, and NPV (besides negative) is higher in the rural area. Like other technologies, LTE will benefit from an adequate infrastructure sharing (see Table 14).

\section{Sensitivity Analysis}

These results are based on assumptions, forecasting, and estimation of several parameters; therefore, it is essential to investigate which are the most significant parameters to influence the results (sensitivity) and, if possible, verify such factors as increased profits or other negative results. With the sensitivity analysis, we can understand the influence of several input parameters (e.g., HH, penetration rates, segments length, bandwidth, retail price, discount rate, trench/duct infrastructure sharing) on the economic indicators results (NPV, IRR, CAPEX, OPEX, and PB).

Comparing the relative importance of variables (Figure 5), we can verify that the number of $\mathrm{HH}$, penetration of $\mathrm{BB}$ subscription, and monthly tariff of Service 2 has a big impact on the NPV of Operator 1 (Region 1). For new entrants (Operator 2), the most significant parameters are distribution segment length, trenching prices, and trench/ duct share. Less sensitive parameters are omitted.

In the LTE operator cases (Figure 6), the demand required per user (Service 2), BB subscription, equipment price, risk free rate, and start market share are the most sensitive variables.

Figure 7 shows the result of the linearly variation $(-50 \%$ to $50 \%$ ) of the input parameters for LTE technology, urban area (Region 1), and Operator 2 (New entrant). For example, if the throughput demand/user (Service 2) decreases 30\%, the NPV will be positive.

\section{Conclusion}

The case study results illustrate the importance of infrastructure sharing for new entrants both in FTTH and LTE. The presented results give important information about the two different solutions in urban and rural areas, indicating that both technologies can provide for sustainable business in Scenario 1. We also identified the critical input parameters for each technology; with this analysis, we examine how technology decisions can change as a function of the input parameters. However, LTE is the better solution for rural areas besides the capacity constraints. The offered capacity per user is the most critical parameter.

\section{References}

[1] H. Galperin, "Wireless networks and rural development: opportunities for latin America," Information Technologies and International Development, vol. 2, no. 3, pp. 47-56, 2005.

[2] J. P. Pereira and P. Ferreira, "A cost model for broadband access networks: FTTx versus WiMAX," in Proceedings of the 2nd International Conference on Access Networks (AccessNets '07), Ottawa, Canada, 2007. 
[3] P. Chanclou, Z. Belfqih, B. Charbonnier et al., "Access network evolution: optical fibre to the subscribers and impact on the metropolitan and home networks," Comptes Rendus Physique, vol. 9, no. 9-10, pp. 935-946, 2008.

[4] O. C. Ibe, Fixed Broadband Wireless Access Networks and Services, John Wiley \& Sons, 2002.

[5] J. P. Pereira and P. Ferreira, "Access networks for mobility: a techno-economic model for broadband access technologies," in Proceedings of the 5th International Conference on Testbeds and Research Infrastructures for the Development of Networks and Communities and Workshops (TridentCom '09), Washington, DC, USA, April 2009.

[6] J. S. Marcus and D. Elixmann, "Regulatory approaches to NGNs: an international comparison," Communications \& Strategies, vol. 69, p. 21, 2008.

[7] F. Kirsch and C. V. Hirschhausen, "Regulation of next generation networks: structural separation, access regulation, or no regulation at all?" in Proceedings of the 1st International Conference on Infrastructure Systems and Services: Building Networks for a Brighter Future (INFRA '08), Rotterdam, The Netherlands, 2008.

[8] P. Xavier, "Geographically segmented regulation for telecommunications," in Proceedings of the Working Party on Communication Infrastructures and Services Policy (OECD '10), p. 77, 2010.

[9] G. B. Amendola and L. M. Pupillo, "The economics of next generation access networks and regulatory governance in Europe: one size does not fit all," in Proceedings of the 18th ITS Regional Conference, Istanbul, Turkey, 2007.

[10] J. P. Pereira and P. Ferreira, "Next generation access networks (NGANs) and the geographical segmentation of markets," in Proceedings of the 10th International Conference on Networks (ICN '11), St. Maarten, The Netherlands, 2011.

[11] J. Rendón, F. Kuhlmann, and J. P. Alanis, "A business case for the deployment of a $4 \mathrm{G}$ wireless heterogeneous network in Spain," in Proceedings of the 18th European Regional International Telecommunications Society, Istanbul, Turkey, 2007.

[12] J. Harno, "Impact of 3G and beyond technology development and pricing on mobile data service provisioning, usage and diffusion," Telematics and Informatics, vol. 27, no. 3, pp. 269 $282,2010$.

[13] EURESCOM, "Techno-economic analysis of integrated wireless-optical networks," in Proceedings of the EURESCOM, pp. 1-71, 2000.

[14] T. Smura, Competitive Potential of WiMAX in the Broadband Access Market: A Techno-Economic Analysis, Helsinki University of Technology, 2006.

[15] H. Sarkissian and R. Schwartz, "A comprehensive WiMAX Operator Business Case Process," 2007.

[16] J. P. Pereira, "The role of WiMAX technology on broadband access networks," in WIMAX, New Developments, U. D. Dalal and Y. P. Kosta, Eds., pp. 17-45, N-TECH, Vienna, Austria, 2010.

[17] Analysys-Consulting, Analysys Cost Model for Australian Fixed Network Services, ACCC, Australia, 2009.

[18] CSMG, Economics of Shared Infrastructure, London, UK, 2010.

[19] B. T. Olsen, D. Katsianis, D. Varoutas et al., "Technoeconomic evaluation of the major telecommunication investment options for european players," IEEE Network, vol. 20, no. 4, pp. $6-15,2006$.

[20] T. Monath, N. K. Elnegaard, P. Cadro, D. Katsianis, and D. Varoutas, "Economics of fixed broadband access network strategies," IEEE Communications Magazine, vol. 41, no. 9, pp. 132-139, 2003.
[21] Analysys-Mason, The Costs of Deploying Fibre-Based NextGeneration Broadband Infrastructure, Broadband Stakeholder Group, Cambridge, UK, 2008, Edited by Analysys-Maso.

[22] M. Kantor, K. Wajda, B. Lannoo et al., "General framework for techno-economic analysis of next generation access networks," in Proceedings of the 12th International Conference on Transparent Optical Networks (ICTON '10), July 2010.

[23] L. E. Braten, "Requirements to and architecture of hybrid broadband access networks," Telektronikk, vol. 2, pp. 22-38, 2006.

[24] H. R. Anderson, Fixed Broadband Wireless System Design, John Wiley \& Sons, Chichester, UK, 2003.

[25] T. Smura et al., Final Techno-Economic Results on Mobile Services and Technologies Beyond 3G, ECOSYS, 2006, Edited by J. Harno.

[26] V. Riihimäki, "Managing Uncertainties in Broadband Investments-Case Studies of Real Options for Rural Area Access Networks," in Department of Communications and Networking, Aalto, Fla, USA, Aalto University, p. 166, 2010.

[27] K. Stordahl, "Broadband demand and the role of new technologies," in Proceedings of the 13th International Telecommunications Network Strategy and Planning Symposium, 2008.

[28] K. Stordahl, "Market development up to 2015," MARCHMultilink architecture for multiplay services, p. 72, 2010.

[29] European-Union, "Europe's digital competitiveness report 2010," Tech. Rep., European Union, Luxembourg, UK, 2010.

[30] R. Prasad and F. J. Velez, WiMAX Networks: Techno-Economic Vision and Challenges, Springer, New York, NY, USA, 1st edition, 2010.

[31] N. K. Elnegaard, K. Stordahl, J. Lydersen et al., "Mobile broadband evolution and the possibilities," Telektronikk, vol. 3, no. 4, p. 11, 2008.

[32] G. Rosston, S. Savage, and D. Waldman, "Household demand for broadband internet service," Communications of the Acm, vol. 54, no. 2, pp. 29-31, 2011.

[33] European-Commission, "Electronic Communications Market Indicators," European Commission, 2011.

[34] Analysys-Mason, "Mobile and fixed broadband: co-habitation or competition?" in Webinar, Analysys Mason, London, UK, 2008.

[35] T. Koonen, "Fiber to the home/fiber to the premises: what, where, and when?" Proceedings of the IEEE, vol. 94, no. 5, pp. 911-934, 2006. 

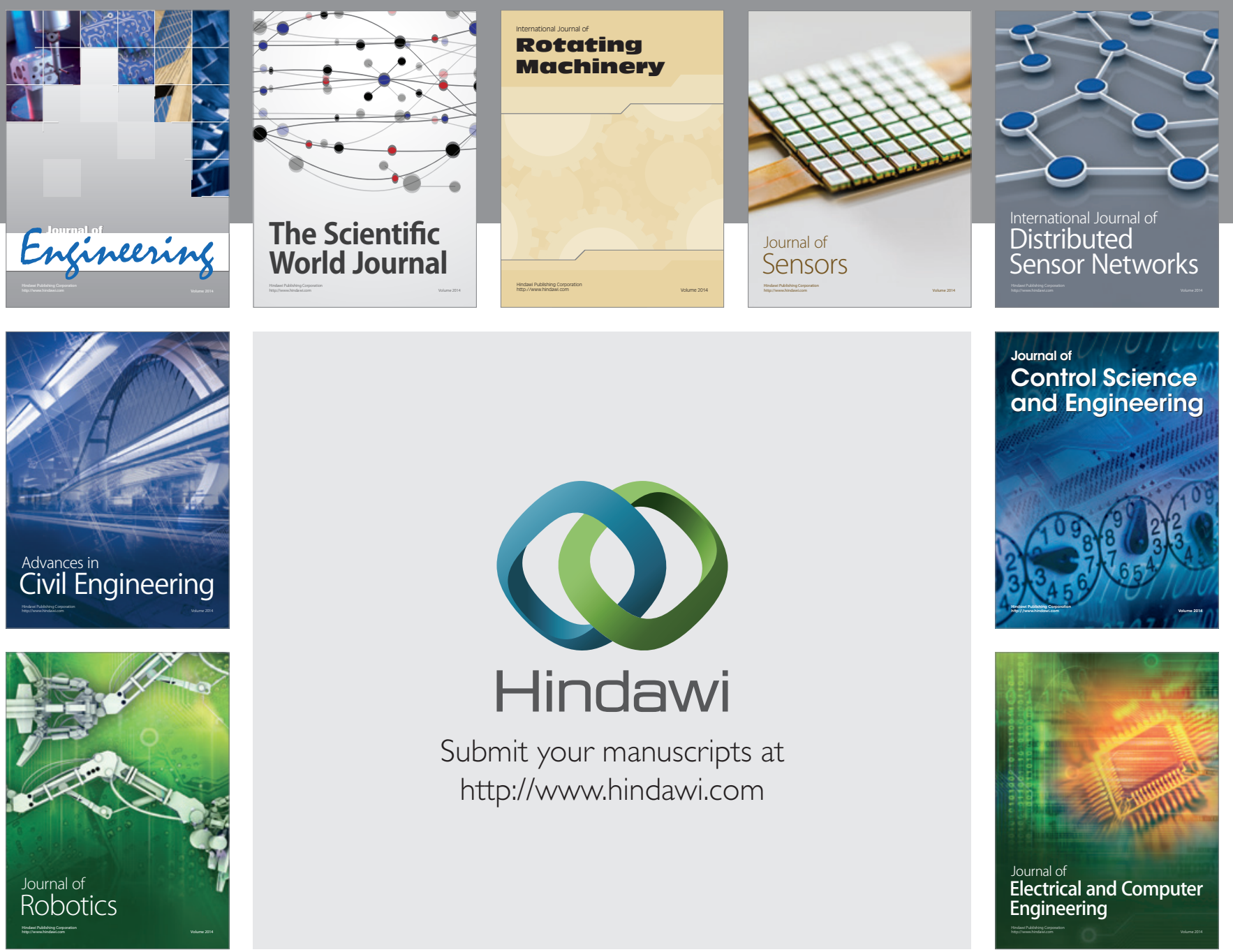

Submit your manuscripts at

http://www.hindawi.com
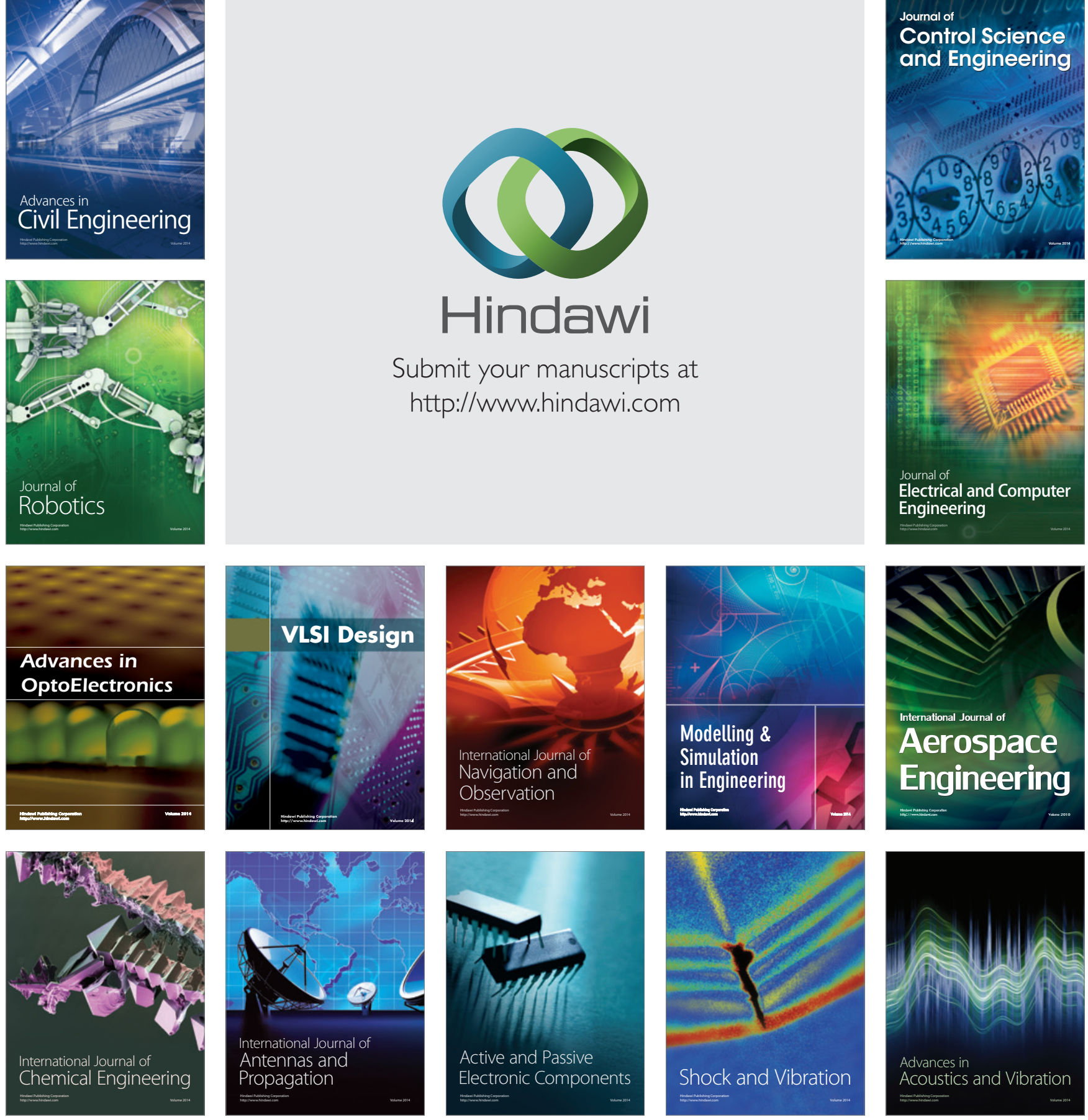